\title{
Uma noção de matriciamento que merece ser resgatada para o encontro colaborativo entre equipes de saúde e serviços no SUS
}

\section{| ${ }^{1}$ Roberto Henrique Amorim de Medeiros |}

Resumo: A literatura e a experiência do trabalho na atenção primária em saúde permitiram ao autor refletir acerca das principais características das práticas de matriciamento das redes de atenção à saúde no contexto do SUS ao longo dos anos. Questionam-se as noções de matriciamento que estruturam práticas de consultoria e supervisão por parte de equipes ou profissionais aos quais se atribui a qualidade de especialistas. Os efeitos dessa relação entre equipes e serviços são discutidos e os benefícios no contexto da gestão e da atenção em saúde são analisados. Sustentado na proposta original de matriciamento em saúde, o artigo estabelece uma problematização que, analisando suas consequências lógicas, acaba por construir uma noção que se diferencia de outra que parece sustentar práticas verticalizadas entre lugares de especialidade e de generalidade. Com o apoio da teoria matemática do cálculo matricial, constrói a noção de matriciamento que pretende contribuir para implementar relações colaborativas entre equipes e serviços com efeitos importantes e resolutivos no registro da atenção e da gestão do cuidado integral da saúde.

> Palavras-chave: matriciamento; saúde; SUS; integralidade; gestão; clínica.
1 Universidade Federal do Rio
Grande do Sul. Porto Alegre-RS,
Brasil. Endereço eletrônico:

robertoamorim80@hotmail.com 
O cuidado integral em saúde pode ser desenhado em qualquer instância, se inspirado pela articulação de três elementos em seu procedimento: acesso, responsabilização e autonomia. O acesso é a condição do cuidado integral: fruto do ganho social da reorganização da saúde no país, cujo princípio de universalidade procura garantir a entrada no sistema como direito de todo o cidadão e dever do Estado. A responsabilização é desmembrada em vínculo e resolutividade: compreende elementos éticos, técnicos e políticos do ato de cuidar da saúde por parte das equipes. Por fim, a autonomia do usuário é o produto do cuidado integral: todo ato em saúde procurará respeitar a singularidade e a cidadania daquele que é cuidado, evitando tutela ou reificação do sujeito que busca atenção a sua saúde.

É no registro da responsabilização que parece situar-se uma das mais importantes problemáticas acerca da reorganização do trabalho em saúde, com o surgimento da lógica de equipes de apoio às unidades de Estratégia de Saúde da Família (ESF) no contexto da Atenção Primária em Saúde (APS) no Sistema de Único de Saúde (SUS). É da responsabilidade das equipes de ESF serem o primeiro contato do usuário com o sistema de saúde por meio de seus serviços. Costuma-se reconhecer que esse nível de atenção pode ser resolutivo em mais de $80 \%$ das necessidades em saúde de uma população (OPAS, 2007). Além disso, é também responsável pela coordenação do cuidado aos seus usuários (indivíduos, famílias, coletividades), de modo a realizá-lo ao longo do tempo mediante projetos de vida singulares. $\mathrm{O}$ vínculo e a resolutividade, portanto, são os parâmetros que norteariam as equipes de saúde segundo o elemento de responsabilização do cuidado integral.

Por uma série de fatores, as equipes da ESF/SUS nem sempre conseguem se responsabilizar adequadamente por seu processo de trabalho, pelo entendimento a respeito da função que ocupam em relação aos pacientes ou pelo auxílio à viabilização do SUS como política pública.

O matriciamento, como lógica de organização do trabalho em saúde, aponta para o segundo tempo lógico do cuidado integral ${ }^{1}$ ao constituir-se como prática de cooperação entre equipes de ESF e suas referências de apoio - setoriais e intersetoriais - e como modo de potencializar o trabalho com os cuidados primários em saúde em toda sua complexidade. É o que parece propor Campos (1999) em seu artigo inaugural acerca da proposta de matriciamento, 
afirmando-o como representante de um novo arranjo que estimula a produção

de novos padróes de relacionamento entre equipe e usuários e que amplia o compromisso dos profissionais com a produção de saúde, à medida que supera obstáculos organizacionais que dificultam a comunicação.

As demandas cotidianamente endereçadas às equipes de ESF no seu território de práticas, bem como suas complexidades, implicam um rol de atos de cuidado que exigem muitos recursos materiais (instrumentos, infraestrutura, profissionais) e imateriais (técnicas, gestão, saberes, ética), dada à variedade de situações de saúde a ser considerada na construção de projetos terapêuticos. A alta complexidade do trabalho em APS é representada pela produção de atos de cuidado em saúde que vão desde as práticas protocolares de uma ação programática, às ambulatoriais da clínica geral médica, às curativas e antropométricas de enfermagem, passando pelo cuidado de famílias em situação de risco e vulnerabilidade, ações de promoção e educação em saúde, participação no controle social e chegando até a clínica da saúde mental e às demandas do contexto dos programas de assistência social. Tudo isso corresponde a práticas diárias da ESF, criada pela Portaria no 648 (BRASIL, 2006), que conta com equipe mínima, composta pelo médico, pelo enfermeiro, pelo agente comunitário de saúde e, em alguns casos, pelo odontólogo.

A criação dos Núcleos de Apoio à Saúde da Família - NASF (BRASIL, 2008) procurou impactar a resolutividade da ESF, ao fornecer-lhe uma equipe de apoio especializado conforme as demandas específicas de cada um dos seus territórios. Concomitantemente, os Centros de Atenção Psicossocial - CAPS (BRASIL, 2001) já existentes passaram a integrar efetivamente o campo da APS na composição da rede de compartilhamento de responsabilidades do trabalho com a ESF e o NASF, supondo a lógica do matriciamento.

Entretanto, mesmo que se suponha uma rede de trabalho compartilhado pelas três equipes instituídas pelas leis e portarias citadas, isso não implica que a operacionalização do encontro colaborativo entre elas esteja definida. Nem mesmo que o entendimento acerca da prática de matriciamento como lógica de articulação da rede seja unívoco ou conduza ao sucesso da estratégia de gestão em rede.

É nesse ponto que o presente artigo procura centrar sua análise. Observase, por meio da experiência própria de trabalho na rede de APS e pelos relatos encontrados em artigos científicos, que a relação entre as equipes no processo de corresponsabilização pelo cuidado integral da saúde dos usuários costuma 
produzir, paradoxalmente, um efeito de desresponsabilização. Efeito de um processo de trabalho precarizado e pouco comunicativo entre equipes e saberes, que pode ser lido nos atos de encaminhamentos excessivos, nas práticas terapêuticas que não privilegiam o vínculo com a equipe da ESF, entre outros.

A construção conceitual presente neste artigo, que pretende contribuir com a problemática do campo do matriciamento em saúde, é produto do seguinte procedimento. A revisão de literatura das três fontes privilegiadas nesse estudo - a saber, o artigo original da proposta de matriciamento de Campos (1999), o conjunto extenso de artigos sobre o apoio matricial em estudos brasileiros e um guia de matriciamento proposto recentemente pelo Ministério da Saúde (BRASIL, 2011) - permitiu uma articulação compreensiva acerca dos entendimentos mais comuns implícitos nas práticas de matriciamento. Esse corpus foi enriquecido com ilustração que procura expressar experiências pessoais de matriciamento achados da revisão de literatura. Por fim, o material reunido permitiu ao autor, por meio de reflexão crítica e de um aspecto lógico-matemático, reconstruir uma noção de matriciamento, a qual parece resgatar a lógica potencializadora da resolutividade na rede de cuidados em saúde.

\section{Os sentidos do matriciamento e sua prática costumeira}

Para construir um argumento sobre a prática comum do matriciamento ao longo do tempo, propōe-se agora o percurso por três fontes textuais de características complementares entresi. Trata-se do artigo fundamental de Campos (1999), no qual o matriciamento surge pela primeira vez como proposta testada de reorganização do trabalho em saúde; de artigos escolhidos sobre aspectos específicos da temática, em complementaridade com a revisão crítica de Athié, Fortes e Delgado (2013), que cobre as publicaçóes acerca do tema do matriciamento em APS no período de 2000 a 2010; e, finalmente, do Guia Prático de Matriciamento em Saúde Mental, do Ministério da Saúde (BRASIL, 2011).

No artigo original, Campos (1999) expõe uma proposta de reorganização do trabalho em saúde baseada em equipes de referência com apoio matricial, correspondente à experiência acumulada durante oito anos em dois municípios do interior de São Paulo e de Minas Gerais. Logo no início do texto, afirma que a cultura e a subjetividade das equipes de saúde no país têm sido construídas a partir da concorrência de paradigmas, como o medicalizante e o da Saúde 
Coletiva, e de saberes, como o psicanalítico e o da Saúde Mental, entre outros.

Nesse contexto, afirma que o processo de trabalho em saúde é produto do estilo de gestão e estrutura de saber-poder circulante. Conclui, então, que o sistema de poder, à medida que seja verticalizado e centralizador, tende a estimular o descompromisso e a alienação no processo de trabalho.

A proposta de equipes de referência e do matriciamento surge como subversão da lógica hierarquizada do sistema de saúde, buscando a cooperação entre equipes e serviços para enriquecer as possibilidades de composição dos projetos terapêuticos individuais. A sugestão de Campos (1999), embora não prescinda de uma relação especializada de apoio a equipes de referência, traz a novidade da horizontalização de serviços e dispositivos de cuidado num projeto terapêutico que pode não ser executado apenas na equipe de referência do usuário. $\mathrm{O}$ matriciamento não se resumiria no encontro de profissionais de duas instâncias que se apoiam para lidar com determinada situação de saúde, mas também poderia ser o arranjo entre recursos ofertados para o cuidado em saúde que ocorrem em serviços distintos. Além de uma equipe de APS contar com o apoio especializado do NASF ou do CAPS, poderia compor planos terapêuticos em que o usuário seria recebido em atividades ofertadas por outros serviços Unidade Básica, Hospital Geral - como um atendimento clínico ou um grupo que trabalhe a partir de aspectos culturais do território. Perceba-se que nessa proposta há um elemento horizontal de oferta de serviços e práticas adequadas a um projeto terapêutico, além do elemento vertical do apoio especializado.

Para o autor, a matriz organizacional seria constituída pelo entrecruzamento de equipes de referência ao usuário (a ESF de hoje) e linhas de apoio matricial compostas não apenas por equipes especializadas (NASF e CAPS de hoje), mas também por uma lista de atividades e serviços oferecidos por profissionais e equipes a ser integrado num projeto terapêutico singular estabelecido entre o terapeuta de referência, o profissional que oferece a atividade matricial e o próprio usuário.

Cabe observar que o elemento horizontal, na concepção de Campos (1999), teria o potencial de alterar a prática de referência e contrarreferência que patrocina a lógica do encaminhamento e sugere o ato de desresponsabilização por parte das equipes de referência dos usuários. Mas, por que elementos fundamentais do matriciamento não teriam se consolidado com o passar do tempo? 
O Guia de Matriciamento do Ministério da Saúde parece tentar resgatar o elemento horizontal da proposta de Campos. Propõe que a horizontalidade ocorra pela reestruturação do sistema de saúde em dois tipos de equipes: de referência e de apoio matricial (BRASIL, 2011, p. 13). Entretanto, em primeira instância, parece que apenas um dos aspectos da horizontalidade de Campos (1999) está contemplado. Verificar-se-á, adiante, se o adjetivo "matricial”, quando atribuído a uma das equipes do sistema de gerenciamento da atenção em saúde, está adequado ou é signo da insistência da verticalização no dispositivo.

Possíveis respostas puderam ser encontradas preliminarmente na revisão literária exaustiva de Athié, Fortes e Delgado (2013), que procurou estabelecer um panorama abrangente das experiências de articulação entre APS e Saúde Mental, no sentido do matriciamento, publicadas durante toda a primeira década deste século.

O cruzamento de descritores gerou cerca de 10.500 publicações. Dessas, apenas as experiências em língua portuguesa foram selecionadas. As 403 publicações elencadas foram submetidas a critérios de exclusão, gerando um corpus de 86 artigos específicos sobre o tema a partir de experiências brasileiras.

A análise crítica do material coletado revelou três enfoques privilegiados nos estudos e relatos acerca da articulação APS e saúde mental. O primeiro diz respeito a artigos escritos a partir da visão dos especialistas. O grupo de 28 artigos, dos 86 estudados, traz concepções da reforma psiquiátrica e ampliação do modelo assistencial além do hospital e das internações. Neles, a articulação com a APS é pensada com a referência prática dos ambulatórios especializados em Saúde Mental e dos CAPS em detrimento da ESF. O segundo enfoque privilegia a visão da APS em 37 artigos. Nessas referências, a preocupação é com os problemas e necessidades mais comuns em Saúde Mental encontrados pelas equipes nesse registro da atenção e a possibilidade de soluções efetivas junto à sua população. O tom dos artigos deixa entrever alguma angústia e preocupação por parte dos profissionais da ESF no trato com o sofrimento psíquico subjetivo de sua clientela. Finalmente, a terceira categoria de publicações, que contou com 21 artigos, traz especialmente relatos do âmbito no qual o matriciamento acontece. A ênfase está na experiência de colaboração com a APS na assistência e na formação de recursos humanos para o trabalho em Saúde Mental. As descrições apontam o cenário de relação entre o matriciador (especialista) e os matriciados (não especialistas). 
A produção bibliográfica no campo do matriciamento, em especial os trabalhos

afins dessa terceira categoria de estudos, encaminha a questão de saber como a organização dos dispositivos de encontro da ESF com profissionais das equipes de NASF e/ou de CAPS acabaram por reproduzir uma lógica verticalizada, pela qual a posição subjetiva das equipes da ESF no encontro matricial parece submetida ao protagonismo da expertise de seus apoiadores.

Em que medida a relação estabelecida comumente na composição prática do matriciamento seria patrocinadora de alguns problemas no que tange à responsabilização pelo cuidado integral em saúde? Essa pergunta fundamental, que resgata a problematização inicial do artigo, não é colocada nesse momento para ser imediatamente respondida, mas para instigar a execução de mais um passo na direção do objetivo de reconstrução conceitual do matriciamento. Parece claro haver a dimensão do encontro no matriciamento. Há necessidade de perquirir que tipo de encontro pode ser esse quando é estruturado sob uma relação supostamente hierarquizada, na interface entre matriciadores e matriciados.

Para escapar da representação - na qual argumentos e conceitos se articulam conferindo sentidos ao objeto - escolheu-se o caminho da ilustração, em que uma produção imagética a respeito do objeto permitirá a elaboração conceitual procurada, em vez de interpretações e metáforas explicativas.

A seguir, será produzida a narrativa de uma cena. Ela tem por função ilustrar posiçôes corriqueiras de equipes de referência e de apoio no registro do encontro matricial. Com ela será possível reconstruir conceitualmente o tema. Se bem sucedida, essa reconstrução tentará regatar noção fundamental que potencializa o matriciamento como prática colaborativa para o cuidado integral em saúde.

\section{Uma narrativa como modo de expressão do encontro matricial em sua suposta atualidade}

No encontro entre uma equipe de referência e outra de apoio, no contexto da atenção primária em saúde (APS), teria sido ouvida a afirmação de que, se a primeira equipe trabalhasse adequadamente a motivação dos pacientes em seguir tratamentos, a segunda proporcionaria $100 \%$ de cura em retorno. O encontro partiu do desejo da equipe de referência de formalizar trabalho integrado na produção do cuidado em saúde de usuários de álcool e outras drogas. O objetivo era aprimorar um trabalho que já se fazia no contexto daquela equipe na APS. 
Quem sabe, se podia fazer melhor com a parceria do CAPS?

Depois de uma primeira visita ao CAPSad (álcool e drogas) de sua referência, aquela equipe obteve notícias sobre o acesso do usuário de drogas àquele espaço de atenção e cuidados. Em seguida, procuraram reunir conhecimentos e práticas já realizadas e sistematizar propostas e perguntas para a equipe do CAPS, para marcar uma reunião na qual se poderia iniciar a composição de uma rede resolutiva ao problema e aprender algo mais a partir da interlocução.

A reunião iniciou de modo natural: pessoas apresentando-se, estudando-se e imaginando o que passaria na cabeça dos demais, que conhecimento teriam e que intençōes demonstrariam no decorrer da conversa. Encontravam-se frente a frente duas malhas de uma possível rede: o posto de saúde e o CAPSad. Rede de compromissos, para início de conversa. Rede de petiçôes, para estabelecer e efetivar um plano de cuidados. A demanda de trabalho em serviços de saúde num país modesto em qualidade de vida dos seus cidadãos é sempre maior do que o potencial em atendê-la. Quando dois serviços se encontram, essa demanda costuma aumentar, pelo simples efeito de visibilidade dos problemas, mas também pelas petições e compromissos (MERHY et al., 1997) que acabam se estabelecendo.

Naquele dia, um dos profissionais da unidade de saúde tomou a palavra para esclarecer que o objetivo inicial seria criar laço de trabalho entre as equipes e não delegar tarefas aos especialistas no problema. A intenção era sublinhar o comprometimento mútuo entre as equipes. Outros comentaram o que já faziam no território e compartilharam conhecimentos locais sobre o tema.

Ao tomar a palavra, um membro da equipe do CAPS ressaltou sua larga experiência no setor. Em seguida, dissertou com aparente propriedade acerca das condições que levam alguém às drogas; trouxe exemplos de atitudes que, por exemplo, um médico da APS deveria tomar frente ao paciente para motiválo; indicou livro sobre como entrevistar e motivar simultaneamente, tudo isso enquanto citava esporadicamente a palavra escuta. Ressaltou, por fim, a necessidade de envolvimento do médico da APS na questão: é sua prerrogativa, sua responsabilidade, e deve ser de sua competência tratar do alcoolismo e das drogas. É a esse integrante do encontro que se deve o crédito da afirmação que inicia o relato desta cena.

Após curto período de silêncio, alguém da equipe de APS reiterou o propósito de estabelecer uma parceria de trabalho para aprimorar o cuidado à situação tão 
prevalente na população do território em que trabalhavam. Um acadêmico do curso de Medicina, que ali cumpria seu estágio, lançou ainda um questionamento sobre a facilidade de tratar quem já está motivado, constituindo, em sua opinião, verdadeira situação problemática quando ocorre o caso inverso. Seu posto e lugar na equipe foram questionados e, em seguida, a resposta seguiu a linha de menosprezo pela sua pouca idade na profissão. Depois disso, apenas um médico da APS ousou tomar a palavra encerrando aquela reunião defensivamente com a lembrança de que nenhum usuário daquela unidade de APS havia sido encaminhado ou estava em atendimento no CAPSad até aquela ocasião. Após essa fala, nada além de despedidas, agradecimentos, cumprimentos e constrangimentos.

A afirmação sobre a certeza do sucesso no tratamento das drogas sob a condição do trabalho prévio a respeito da motivação para o tratamento fora, sem dúvida, uma frase de efeitos. Mas, quais? Desarticulação, desmotivação e pouca escuta. Nada mais se produziu no sentido da articulação que se buscava.

Parece importante refletir sobre o que determina tais efeitos. Para tanto, é preciso diferenciar o conteúdo manifesto da narrativa, que não pode ser universalizado - pouco servindo à construção conceitual expressiva do fenômeno em pauta - do outro conteúdo, estruturante, que organiza a cena. Ou seja, a ilustração pouco servirá se tomada em sua literalidade e como representação exemplar. $\mathrm{O}$ encontro de caráter colaborativo do matriciamento pode resultar numa infinidade de efeitos, não apenas categorizáveis em bons ou maus, para a corresponsabilização no cuidado em saúde.

Há, entretanto, a possibilidade de formalização de um elemento da cena que tem estruturado o encontro de profissionais, equipes e serviços no campo do matriciamento em saúde ao longo dos anos de suas práticas. Trata-se daquilo que situa a suposição de saber acerca do problema em apenas um dos elementos do encontro. Suposição compartilhada frequentemente pelas outras partes.

Por meio de recurso expressivo, a cena procura dar visibilidade a efeitos conjugados de verdade e poder oriundos do exercício de um saber privilegiado sobre outros. $\mathrm{O} a b$-uso da suposição de saber costuma promover desequilíbrio nas relações estabelecidas por determinado laço social. No caso do matriciamento, um laço que organiza encontros para a produção compartilhada de trabalho.

A respeito do matriciamento, é possível afirmar: há encontro e há saberes em disputa. Há encontro de saberes. Há, portanto, produção de verdade e efeitos de 
poder. Resta, agora, tentar formalizar uma resposta ao problema de encontrar noções de matriciamento que ora o têm sustentado como prática hierarquizada com privilégio da expertise, ora como prática horizontal e colaborativa como parece ter sido a intenção original de sua proposição (CAMPOS, 1999).

\section{Uma noção de matriciamento que merece ser resgatada}

Mesmo que inadvertidamente, toda prática materializa uma posição ideológica ou reproduz um imaginário construído como ideal de seu tempo. Assim, o privilégio do saber especializado, esteio da verdade no imaginário contemporâneo, pode parecer natural à relação matricial, condição que parece implicar que aquela relação acabe se tornando verticalizada, como indica a literatura e algumas experiências comuns no campo de práticas. Encontra-se, de um lado, uma equipe que não se autoriza a proceder ao ato de cuidado sem contar com o apoio supostamente especializado, e, de outro, aquela que, por sua vez, se autoriza pela sua experiência a ser propositiva do que deve ser feito e dos caminhos mais corretos e seguros para tanto.

O matriciamento recebe essa denominação numa clara referência à noção de matriz. Entretanto, a palavra matriz, por sua função significante, não assume apenas um sentido possível. A relação matricial parece ter sido reproduzida no tempo por uma noção de matriz que remete ao sentido de máter. Essa noção promove a mesma relação estabelecida entre matriz e filial, a qual evidencia uma hierarquia de lugares que cada qual ocupa.

O privilégio do saber especializado não é o único efeito possível dessa noção. Supor uma célula máter na relação matricial é o que parece produzir um fato de linguagem que tem denominado como equipe matricial apenas aquela cujo fundamento é a especialidade. É extremamente comum ou naturalizado encontrarmos na literatura a denominação "matricial" atribuída às equipes de NASF ou de CAPS (BRASIL, 2011). É possível que o próprio leitor, nesse momento, já tenha acolhido com naturalidade essa nomenclatura. Isso não deve implicar, entretanto, que outras noções não sejam investigadas e consideradas.

A noção de máter no campo do matriciamento parece reproduzir a relação materno-infantil entre as equipes do NASF e da ESF. Frequentemente, a equipe especializada tende a atuar a partir do lugar de quem deve acolher, ensinar, elogiar ou corrigir a outra. Não é incomum que os efeitos desse tipo de relação 
reproduzam a tutela que infantiliza ou a reprimenda que põe fim ao diálogo.

Levando adiante a metáfora, se o filho ainda tem poucos anos de vida (experiência), ele vai se mostrar mais dócil aos cuidados e preceitos da mãe, ao passo que, na sua adolescência, tenderá a não dar ouvidos às recomendações. Nesse sentido, caso se trate de uma equipe "adulta" a ser "matriciada", esta possivelmente submeterá a equipe matriz/matricial às suas concepções, seu modo de viver, numa clara afirmação do saber de quem já assume posições autônomas frente a sua vida.

Em quaisquer das situações anteriores, o resultado parece equivocado, se observarmos os princípios que nortearam a ideia do matriciamento (CAMPOS, 1999). Afirma-se, portanto, a pertinência de construir outra noção que resgate o fundamento da proposta para servir de alternativa conceitual à produção de práticas no registro do matriciamento.

No campo da matemática, a teoria das matrizes e determinantes data de dois séculos a.C. Sua motivação situa-se na resolução de sistemas lineares compostos por mais de uma equação nos quais existe um número $n$ de incógnitas (GIOVANNI; BONJORNO; GIOVANNI Jr., 1994). A aplicação da teoria das matrizes é larga nos campos das ciências físicas, econômicas e da engenharia, com destaque para a área da informática. Em que a teoria do cálculo matricial pode auxiliar o campo das relações entre equipes, serviços e profissionais em saúde?

A seguir, apresentar-se-ão três observações a respeito da teoria matemática das matrizes. Elas tratam da teoria básica do cálculo matricial, cujo interesse para este artigo não se situa no campo da matemática, mas como analogia útil para construir uma noção que inspire as práticas colaborativas no campo da saúde.

Primeira: o sentido matemático de matriciamento diz respeito ao encontro de sistemas equacionados. A montagem de uma matriz composta por dois sistemas, por exemplo, pode se dar da seguinte forma:

$$
\begin{aligned}
& \left\{\begin{array}{l}
5 x+3 y=20 \\
3 x-2 y=32
\end{array}\right. \\
& {\left[\begin{array}{lr}
5 & 3 \\
3 & 2
\end{array}\right] \cdot\left[\begin{array}{l}
x \\
y
\end{array}\right]=\left[\begin{array}{l}
20 \\
32
\end{array}\right]}
\end{aligned}
$$


Segunda: à medida que uma matriz seja formada por uma sequência de elementos dispostos em certo número de linhas e colunas, a notação matemática de um elemento da matriz escreve-se $A_{i j}$, que define a posição do elemento no cruzamento da linha i com a coluna $\mathrm{j}$. Assim $\mathrm{A}_{11}$ define a posição do elemento da linha 1 e na coluna 1 da matriz e, por conseguinte, $A_{12}$ vai definir a posição do elemento da linha 1 e na coluna 2 :

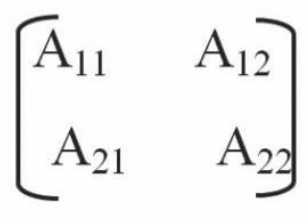

Ou seja, a notação da matriz (Aij), diz respeito ao cruzamento de determinados lugares, posicionamentos.

Terceira: o que vai determinar qual é o elemento que ocupará cada posição na construção da matriz é uma lei, que é proposta pela expressão matemática encontrada no lado direito da fórmula e que, ao ser aplicada, estabelece o elemento e sua posição na matriz, por exemplo, $A i j=2 i+j$. Assim, ao se aplicar a lei $(2 i+j)$ para o elemento da posição A11 (nesse caso: $i=1$ e $j=1$ ), resulta: $2(1)+$ $1=3$. Calculando-se pela lei $(2 \mathrm{i}+\mathrm{j})$ os 4 elementos de uma matriz hipotética de duas linhas e duas colunas, obtém-se a construção da seguinte matriz:

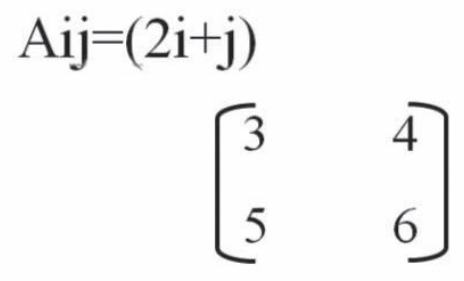

Desse modo, para o equacionamento dos sistemas relacionados matricialmente, e para o posicionamento que define a articulação entre os elementos, existe um organizador que estabelece as relações entre linhas e colunas que compõem uma matriz.

As três observações a respeito das matrizes, tal como concebidas no campo da matemática, parecem ser potentes para construir outra noção para o encontro chamado de matriciamento no registro das práticas de atenção e gestão em saúde. 
A primeira observação ressalta que o trabalho com matrizes na matemática busca estabelecer um modo de operar com dois ou mais sistemas a partir de uma relação de equação para que se determinem seus elementos incógnitos. De modo aproximado, também podemos admitir tratar-se o campo do matriciamento em saúde do encontro de dois ou mais sistemas com suas incógnitas.

As equipes de saúde e seus processos de trabalho constituem sistemas (sistemáticas de organização) e incógnitas (aquilo que não está explícito no universo das situações-problemas a serem resolvidas e o modo informal de proceder no cotidiano de trabalho). Consequentemente, é a elucidação de verdadeiras incógnitas inscritas numa situação-problema a ser resolvida por meio do encontro de dois ou mais sistemas (ESF, NASF e/ou CAPS, por exemplo.) o que está em jogo na proposta do matriciamento. Segundo essa concepção, é a equação (relação de igualdade a ser elucidada) entre os sistemas (equipes ou serviços) o que permite resolver aquilo que se desconhece da natureza dos processos de trabalho, das relações institucionais e pessoais de uma equipe e que respondem pelo bom ou mau andamento de suas práticas. Aí está o primeiro fundamento patrocinado por essa noção de matriz: a necessidade do estabelecimento de uma equação entre as equipes para que as incógnitas (os elementos-chave para a solução) possam ser encontradas e elucidadas na lógica do matriciamento. A relação estabelecida entre as equipes no matriciamento é o que define o sucesso da utilização de certos dispositivos, como a construção compartilhada do caso, a consulta conjunta, a educação permanente, a análise institucional. Todos representando métodos horizontais (equacionados) de relação entre equipes (sistemas) no procedimento matricial.

Não obstante, cabe observar que a equação, no contexto do cálculo matricial, embora sugira uma relação de igualdade, não produz identidade. Esse fato conceitual é importante por nos preservar do equívoco que seria assumir que equipes diversas como as de ESF e de NASF sejam concebidas sem respeito a suas singularidades. A igualdade na relação estabelecida pela matriz não supõe identidade. É o que conota a segunda observação feita acima. O estabelecimento de uma matriz matemática se dá pelo encontro de elementos componentes de linhas e colunas. Essa condição sugere que uma equipe matricial seja, na verdade, o que resulta do encontro, no território, de equipes, serviços ou profissionais de referência com os de apoio. Parece claro que os lugares e posicionamentos desses 
elementos são específicos e diferentes entre si na construção da equipe matricial, embora sua relação deva ser equacionada.

Essa necessidade é, finalmente, o objeto da terceira observação. Trata-se do que fundamenta a matriz: uma lei que ao ser estabelecida determina uma equação, mas também, lugares distintos. Perceba-se que uma lei tem o potencial de fazer operar determinada estrutura de relaçóes de modos infinitos e diversos entre si, à medida que seus pressupostos sejam conservados. Por isso, aquilo que determinaria o matriciamento não se trata de uma regra a ser seguida em todos os casos. Esse fato promoveria sempre uma mesma ordem para a relação entre seus elementos.

$\mathrm{O}$ último aspecto da noção que se constitui a partir da matemática para o matriciamento parece fundamental. Obtém-se, portanto, que o matriciamento ocorre pelo encontro operativo de dois sistemas (equipes, serviços, profissionais) com suas incógnitas (problemas, processos e relações de trabalho), a partir de posições distintas. É a esse encontro (de dois ou mais sistemas) que se propõe a denominação de matricial, cujo modo de operar sustenta-se num pressuposto lógico (lei) que o faz trabalhar colaborativamente. A cada situação em que se estabelece a necessidade do matriciamento caberia determinar: que lei coloca em marcha seus elementos? E, em seguida, perguntar: trata-se de uma lei ou imposição de regra?

\section{Possíveis linhas de reflexão presentes e futuras acerca da responsabilização no registro do cuidado integral a partir das noçóes de matriciamento}

Vínculo e resolutividade. Situou-se nesse tempo lógico da estruturação do cuidado integral a problemática de onde se origina a produção da ideia e da prática do que se convencionou chamar matriciamento. Assumiu-se que ele opera no tempo de responsabilização de um processo de cuidado integral em saúde. A questão da responsabilização, que se endereça à clareza, ao comprometimento e à ética do ato profissional de cuidado das equipes de saúde dentro de um sistema, pode ser desmembrada em duas linhas de pensamento.

Parte-se da constatação de uma dificuldade situada no tempo lógico da responsabilização - vínculo e resolutividade - no seio da articulação de práticas e serviços do sistema de saúde, situação em que o matriciamento deve advir em resgate. 
Embasados na revisão de 37 artigos da última década sobre o tema (ATHIÊ; FORTES; DELGADO, 2013), encontramos a necessidade de apoio às equipes de atenção primária devido à multiplicidade de situações com que são convidadas a lidar na posição de primeiro contato com o sistema de saúde. É fraca a conclusão acerca do motivo da pouca resolutividade ocorrer devido ao excesso de demandas que sobrecarrega as equipes de saúde desse contexto, pois se encontra o mesmo excesso em outros registros do sistema, seja em hospitais gerais ou em serviços especializados.

Parece mais adequado partir da questão da complexidade das situações de saúde que a APS acolhe diariamente e que a excedem em termos de seu potencial de ação. Ao que parece, essa complexidade não é fruto do recrudescimento da situação de saúde das pessoas. Em verdade, comparando a condição sanitária do nosso país nos últimos sessenta anos, constata-se um incremento significativo na saúde e na expectativa de vida da população. O que parece ter mudado é a construção coletiva acerca das novas demandas em saúde (PINHEIRO; MATTOS, 2005), a posição cidadã do usuário do SUS no controle social (CECCIM, 2007) e a rejeição do discurso hegemônico na construção de objeto do campo da saúde, a saber, o medicalizante (CAMARGO, 1993; TESSER, 2006; MACHADO; LESSA, 2012). Hoje, quando uma família chega à sua Unidade de Saúde de referência para se queixar do rendimento escolar de uma criança, o encaminhamento ao psicólogo ou neurologista de um serviço de apoio é o ato mais rasteiro de uma clínica minimamente adequada. Nesse mesmo caso, o discurso da integralidade do cuidado em saúde permite perguntar pela nutrição, pela relação familiar, pelas condiçōes de subsistência da família, além da questão biológica e cognitiva. Esse ato geraria outras necessidades de atenção e plano terapêutico do que uma consulta e um medicamento.

Assim sendo, a complexidade das situações de saúde é uma construção histórica, além de biológica, o que passa a implicar outros atos de responsabilização por parte do sistema. O matriciamento auxilia nesse quadro de novas condiçóes da clínica na atenção primária e da promoção de saúde. Mas qual acepção de matriciamento?

A acepção original de Campos (1999), já observada, sugere que é a articulação em rede de serviços e práticas o que responderia às necessidades de um projeto terapêutico de saúde integral para comunidades e indivíduos. Por essa via, a 
desresponsabilização, entendida como fruto de dificuldades complexas situadas no compasso dos estabelecimentos de compromisso de vínculo e resolutividade entre usuários e serviços, parece ser mais bem entendida, nem tanto pelo sentido de incompetência que o termo sugere, mas pela dificuldade de articulação matricial na rede de saúde.

$\mathrm{Na}$ segunda linha de pensamento, sobre o problema situado no tempo lógico da responsabilização, ${ }^{2}$ é preciso colocar em análise o discurso técnico da expertise. A posição enfática de matriciador, atribuída à equipe ou profissional de apoio especializado (seja em Saúde Mental, em clínicas médicas, em serviço social, em arte etc.), sugere identificação do saber-fazer nesse lugar. Por que isso parece acontecer?

O Guia de Matriciamento (BRASIL, 2011, p.14) cunha uma expressão que acaba servindo de bandeira àqueles que, com alguma crítica acerca da clínica de curto alcance que se pratica há tempos no campo da saúde e ainda é corriqueira na APS, posicionam-se contrários ao atendimento clínico: o apoio matricial é distinto do atendimento realizado por especialista dentro de uma unidade de atenção primária tradicional. Essa frase, numa análise menos simplista, parece compor condição necessária, mas não suficiente. Ela está ali para marcar uma diferença, não para estabelecer a regra: a equipe matricial não realiza atendimentos. A diferença é necessária para que o matriciamento não se torne reprodução daquilo que já existia antes dele, ou seja, a clínica da especialidade e a transferência de responsabilização no atendimento. Em outras palavras, a reprodução de uma clínica medicalizada. ${ }^{3}$ No entanto, o sentido da frase não parece fazer disso uma condição suficiente, à medida que não deveria estar vetado que o especialista efetivamente realize o atendimento necessário, segundo seu saber-fazer, quando isso é pertinente ao plano terapêutico em cada caso ou situação. Nesse caso, considerando que o saber técnico especializado se consolidou como lócus da verdade no espírito de nosso tempo e àquele que o representa é desestimulado o fazer, pergunta-se: quem se responsabiliza?

Outro problema importante parece ser como determinar se o atendimento especializado só deva ser realizado fora de uma unidade de APS? Em artigo cujo intento é compartilhar um "modelo" de matriciamento (BARBAN; OLIVEIRA, 2007), a apresentação da proposta por meio de fluxograma permite acompanhar a trajetória do caso sob os cuidado da unidade de saúde quando não há resolutividade. 
É digno de nota e reflexão observar que, em certo ponto do processo, não há diferença da lógica de fluxo, seja quando este sugere encaminhamento ao especialista, seja quando se remete à suposta equipe matricial.

As decorrências e efeitos no registro da responsabilização - vínculo e resolutividade - já foram indicados anteriormente, à medida que a especialidade como ideia-força na contemporaneidade acaba por representar em si o veredictum. Como criticar a lógica do encaminhamento, que em muitos casos é causa da desvinculação do paciente da coordenação do cuidado por parte de sua equipe de referência, se o discurso da especialidade desautoriza o saber-fazer da equipe de cuidados primários?

Nesse ponto da elaboração é possível observar que as condições simbólicas que promovem a atribuição do termo matricial a apenas uma das partes envolvidas no processo é sintoma (sinal) da operação da noção de máter. Entretanto, evidenciase a necessidade de lidar com a complexidade das situaçóes de saúde enfrentadas pela APS a partir de um arranjo colaborativo em que é tecida uma rede. Campos (1999) reforça a necessidade de uma mudança gerencial dos serviços de saúde para que se produza outra cultura a partir de novos arranjos, por meio dos quais circulem com mais fluidez a comunicação e a cooperação. Propõe, ainda, que o matriciamento tenha o potencial de modificar com vantagens a lógica hierarquizada de gestão em saúde. As condições e propostas originais de Campos, como se pode perceber, implicam lei, não regra. As concepções de operação em rede podem ser variadas e criativamente inventadas. A noção matemática de matriz parece permitir estabelecer leis que ordenam modos de proceder, o que preserva com vantagens a proposta aberta que recebeu o nome de matriciamento no campo da saúde. Por meio dessa noção, é possível contribuir para uma discussão que parte da proposta de que o matriciamento seja o ato resultante de relação equacionada entre linhas de apoio e colunas de referência em cujo arranjo não há suposto privilégio de um tipo de saber; e o fazer passa a estar livre para ser compartilhado. $\mathrm{O}$ estabelecimento da equipe matricial, portanto, dar-se-ia no exato instante em que a equipe de referência e a equipe de apoio iniciassem seu trabalho colaborativo.

É fundamental perceber que a escolha das noções com que se opera em determinado campo não explicita os operadores de modo a funcionarem como elementos prêt-à-porter, nem, tampouco, que essa escolha seja objeto consciente 
daqueles envolvidos no trabalho em rede. Cada noção vai determinar atos e posiçōes subjetivas diferenciadas, mas apenas ao se materializarem em práticas e teorias.

Reafirma-se, portanto, o potencial de resgate da ideia original que possui a noção matemática de matriz para inspirar o pensamento e as práticas da proposta de matriciamento, e a necessidade de rejeitar a regra produtora de modelos e posições cristalizadas em detrimento da lei libertadora dos elementos e sistemas equacionados na equipe matricial. Lei que não pode ser inscrita em um manual, pois deve se escrever em cada caso em que o matriciamento seja convocado, para que cumpra o papel originalmente intuído por Campos (1999).

Resta manifestar o desejo de que este esforço de construção conceitual sirva como contribuição ao debate de ideias, se compartilhado com colegas profissionais e usuários dos serviços de saúde, com os que operam o matriciamento em suas práticas, com alunos dos cursos do campo da saúde, assim como com aqueles interessados em análise institucional ou gestão em saúde. A noção de matriciamento construída neste trabalho também indica o equívoco da dissociação entre papéis da gestão e controle social daqueles da atenção e formação no campo da saúde. Uma pergunta ainda insiste: que noção de matriz é a mais frequente hoje no campo das práticas colaborativas no SUS?

\section{Referências}

ATHIÉ, K.; FORTES, S.; DELGADO, P. G. G. Matriciamento em saúde mental na Atenção Primária: uma revisão crítica (2000-2010). Revista Brasileira de Medicina de Familia e Comunidade. v. 8, n. 6, p. 64-74, 2013. Disponível em: <http://dx.doi.org/10.5712/ rbmfc8(26)536>. Acesso em: 16 set 2013.

BARBAN, E.; OLIVEIRA, A. O modelo de assistência da equipe matricial de saúde mental no Programa de Saúde da Família do município de São José do Rio Preto. Arquivos de Ciências da Saúde, v. 14, n. 1, p. 54-65, jan/mar. 2007.

BRASIL. Decreto-Lei no ${ }^{\circ}$ 10.216. Dispõe sobre a proteção e os direitos das pessoas portadoras de transtornos mentais e redireciona o modelo assistencial em saúde mental. Brasília, de 6 de abril de 2001.

Ministério da Saúde. Guia prático de matriciamento em saúde mental / Dulce Helena Chiaverini (Org.). Brasília: Centro de Estudo e Pesquisa em Saúde Coletiva, 2011.

Portaria no 648. Aprova a Política Nacional de Atenção Básica, estabelecendo a revisão de diretrizes e normas para a organização da Atenção Básica para o Programa Saúde da Família (PSF) e o Programa Agentes Comunitários de Saúde (PACS). Brasília, 28 de março de 2006. 
24 de janeiro de 2008.

CAMARGO Jr., K. R. Racionalidades médicas: a medicina ocidental contemporânea. Rio de Janeiro: IMS/UERJ, 1993.

CAMPOS, G. W. S. Equipes de referência e apoio especializado matricial: um ensaio sobre a reorganização do trabalho em saúde. Ciência e Saúde Coletiva, Rio de Janeiro, v. 4, n. 2, p. 393-403, 1999.

CECCIM, R.B. Invenção da saúde coletiva e do controle social em saúde no Brasil: nova educação na saúde e novos contornos e potencialidades à cidadania. Estudos Universitários. v. 33, n. 1, p. 29-48, 2007.

GIOVANNI, J. R.; BONJORNO, J. R.; GIOVANNI JR., J. R. Matemática Fundamental, vol. único. São Paulo: FTD, 1994.

MACHADO, L. V.; LESSA, O. S. Medicalização da vida: ética, saúde pública e indústria farmacêutica. Psicologia e Sociedade v. 24, n. 3, 2012.

MATTOS, R. A. Cuidado prudente para uma vida decente. In: PINHEIRO, R.; MATTOS, R. A. (Orgs.). Cuidado: as fronteiras da integralidade. 3. ed. Rio de Janeiro: IMS-UERJ, 2006.

MERHY, E. E. Em busca de ferramentas analisadoras das tecnologias em saúde: a micropolítica do trabalho vivo em saúde. In: MERHY, E. E.; ONOCKO, R. (Org.). Agir em saúde: um desafio para o público. São Paulo: Hucitec, 1997.

ORGANIZAÇÃO PAN-AMERICANA DE SAÚDE. Renovação da Atenção Primária em Saúde nas Américas. In: DOCUMENTO de Posicionamento da OPAS e OMS. Brasília, DF, 2007. Disponível em:http://www.parlatore.com.br/centrocolaborador/images/online/ arquivo_renovacao_atencao_primaria_Saude_americas.pdf. Acesso em: 10 maio 2014.

PINHEIRO, R.; MATTOS, R. A. de. Construção Social da Demanda: direito à saúde, trabalho em equipe, participação e espaços públicos. 1a ed. Rio de Janeiro: Cepesc, 2005.

TESSER, C. D. Medicalização Social: o excessivo sucesso do epistemicídio moderno na saúde. Interface - Comunicação, Saúde, Educação, v. 10, n. 19, p. 61-76, 2006.

\section{Notas}

${ }^{1} \mathrm{O}$ cuidado integral pode ser compreendido em três tempos lógicos: instante de acolher o pedido do usuário (acesso), tempo de responsabilização pelo cuidado (vínculo e resolutividade) e momento de concluir o ato de cuidado lançando no futuro seus efeitos (autonomia).

${ }^{2}$ Vide nota 1.

${ }^{3}$ Importante observar que este termo não se refere apenas aos atos de uma clínica médica (cf. MATTOS, 2006). 


\section{Abstract}

A notion of the matricial practice to be rescued for the collaborative encounter between health teams and services in the SUS

The literature and experience of working in primary health care allowed the author to reflect on the main features of the matricial practices of health care networks in the context of the SUS over the years. Matricial practice current notion seems to put forward consulting practices and supervision by teams or professionals to whom the quality of experts is assigned. The effects of this relationship between teams and services are discussed and the benefits in the context of management and health care are analyzed. Sustained in the original proposal of matricial practice, the article establishes a problematization that derives logical consequences to build a notion that is different from that sustained the barren relationship between specialists and generalists. With the support of the mathematical theory of matrix calculus, it builds the concept of matricial practice that could contribute to implement collaborative relationships between teams and services with important and resolving effects in the field of care and management of comprehensive health care.

> Key words: matricial practice; SUS; integrality; management; clinic. 